5. Parilla M, Kadri S, Patil SA, et al. Integrating a large next-generation sequencing panel into the clinical diagnosis of gliomas provides a comprehensive platform for classification from FFPE tissue or smear preparation. J Neuropathol Exp Neurol 2019; 78: 257-67.

6. Yan H, Parsons DW, Jin G, et al. IDH1 and IDH2 mutations in gliomas. N Engl J Med 2009; 360: 765-73.

7. Synhaeve NE, van den Bent MJ, French PJ, et al. Clinical evaluation of a dedicated next generation sequencing panel for routine glioma dignostics. Acta Neuropathol Commun 2018; 6: 126.

8. Louis DN, Giannini C, Capper D, et al. cIMPACT-NOW update 2: diagnostic clarifications for diffuse midline glioma, H3K27M-mutant and diffuse astrocytoma/anaplastic astrocytoma, IDH-mutant. Acta Neuropathol 2018; 135: 639-42.

DOI: https://doi.org/10.1016/j.pathol.2020.12.008

\section{Mycobacterial spindle cell pseudotumour of the brain in an immunocompetent adult}

Sir,

Mycobacterial spindle cell pseudotumour is a rare tumourlike lesion that predominantly occurs in immunocompromised individuals, especially those with HIV infection. Most commonly described in the lymph nodes, this neoplastic mimic has also been reported in various other anatomical locations like skin, soft tissue, bone marrow, spleen, retroperitoneum and lungs. Brain is a rare site for mycobacterial spindle cell pseudotumour with only five documented cases. ${ }^{1-5}$ Here, we describe the second case of mycobacterial spindle cell pseudotumour involving the brain in an adult lacking any evidence of immunosuppression.

A 53-year-old male presented with evening rise in temperature, night sweats and weight loss (about $10 \mathrm{~kg}$ in 2 months) since September 2019. One month later, he developed slurred speech, deviation of angle of mouth to left and right upper limb weakness. For these symptoms he was evaluated elsewhere with magnetic resonance imaging (MRI) which showed multiple intra-axial space occupying lesions, the largest measuring $5.5 \times 2.2 \mathrm{~cm}$ in the right occipital lobe. The lesions were hypointense to isointense on T2-weighted and FLAIR images and hyperintense on diffusion weighted images. The lesions showed thick ring and nodular postcontrast enhancement (Fig. 1A-D). He was referred to our institute and treatment with anti-tubercular drugs along with corticosteroid was started. Following this, there was symptomatic improvement. However, after 4 months, he had an episode of seizure. A repeat MRI at this point showed no change in the size of the lesions.
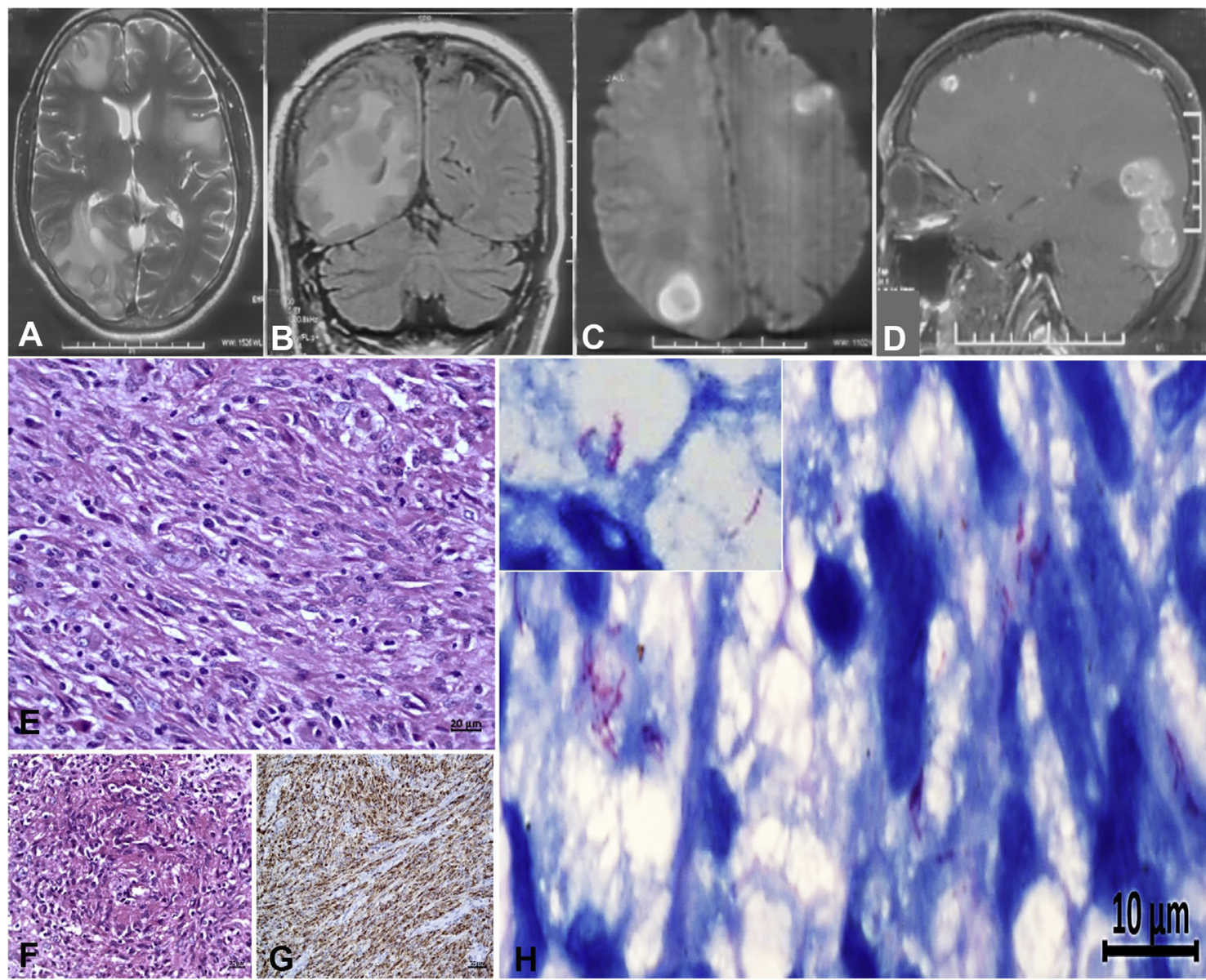

Fig. 1 Imaging and histopathology findings: (A) MRI showing multiple intra-axial lesions that are hypointense to isointense on T2-weighted image and (B) FLAIR sequence. (C) The lesions are hyperintense in diffusion weighted image with (D) thick ring and nodular post-contrast enhancement. (E) Histopathology shows a lesion with fascicles of spindle cells admixed with lymphocytes, plasma cells and (F) few ill-formed granulomata (H\&E). (G) The spindle cells are diffusely positive for CD68 (immunoperoxidase). (H and inset) Acid-fast bacilli were detected on Ziehl-Neelsen stain. 
Table 1 Review of literature of mycobacterial spindle cell pseudotumour in the brain

\begin{tabular}{|c|c|c|c|c|c|c|}
\hline Study & Age/sex & Clinical presentation & Site & Species & Immune status & Treatment and follow-up \\
\hline Morrison et al. ${ }^{1} 1999$ & $38 \mathrm{y} / \mathrm{M}$ & $\begin{array}{l}\text { Headache, slurred speech, } \\
\text { nystagmus, ataxia for } 2 \text { months }\end{array}$ & - & $\begin{array}{l}\text { Mycobacterium avium } \\
\text { intracellulare }\end{array}$ & $\begin{array}{l}\text { Sarcoidosis on corticosteroids } \\
\text { (intermittent) } \\
\text { Low CD4 count } \\
\text { HIV-negative }\end{array}$ & $\begin{array}{l}\text { ATT } \\
\text { Multiple surgical debridement } \\
\text { Good outcome } \\
\text { FU: not available }\end{array}$ \\
\hline Phowthongkum et al. ${ }^{2} 2008$ & $40 \mathrm{y} / \mathrm{M}$ & $\begin{array}{l}\text { Right hemiparesis, progressive } \\
\text { truncal ataxia, and vertigo for } 1 \\
\text { month }\end{array}$ & $\begin{array}{l}\text { Multiple lesions in the left } \\
\text { cerebral peduncle and } \\
\text { medulla }\end{array}$ & $\begin{array}{l}\text { Mycobacterium haemophilum, } \\
\text { Mycobaterium simiae }\end{array}$ & $\begin{array}{l}\text { HIV-positive } \\
\text { Low CD4 count }\end{array}$ & $\begin{array}{l}\text { Partial resection of lesion in left } \\
\text { medulla } \\
\text { ATT } \\
\text { ART } \\
\text { FU: } 3 \text { months post-surgery with } \\
\text { residual neurological deficits }\end{array}$ \\
\hline Sadek et al. ${ }^{3} 2008$ & $63 \mathrm{y} / \mathrm{M}$ & $\begin{array}{l}\text { Headache and word finding } \\
\text { difficulties for } 4 \text { months }\end{array}$ & Left frontal lobe & $\begin{array}{l}\text { Mycobacterium avium } \\
\text { intracellulare }\end{array}$ & $\begin{array}{l}\text { Pulmonary sarcoidosis (not on } \\
\text { treatment) } \\
\text { HIV-negative } \\
\text { No evidence of } \\
\text { immunocompromised state }\end{array}$ & $\begin{array}{l}\text { Resection } \\
\text { ATT } \\
\text { FU: } 1 \text { year with clinical and } \\
\quad \text { radiological resolution }\end{array}$ \\
\hline de Oliveira et al. ${ }^{4} 2015$ & $41 \mathrm{y} / \mathrm{M}$ & $\begin{array}{l}\text { Productive cough, fever, night } \\
\text { sweats, and weight loss for } \\
1 \text { month }\end{array}$ & $\begin{array}{l}\text { Two occipital and one } \\
\text { temporal lobe lesions }\end{array}$ & Mycobacterium tuberculosis & $\begin{array}{l}\text { HIV-positive } \\
\text { Low CD4 count } \\
\text { Pulmonary and cervical lymph } \\
\text { nodal tuberculosis }\end{array}$ & $\begin{array}{l}\text { ATT } \\
\text { ART } \\
\text { Resection of temporal lesion } \\
\text { FU: not available }\end{array}$ \\
\hline Lim et al. ${ }^{5} 2016$ & $66 \mathrm{y} / \mathrm{M}$ & $\begin{array}{l}\text { Neck pain and ataxia for a few } \\
\text { weeks }\end{array}$ & Right cerebellar hemisphere & $\begin{array}{l}\text { Mycobacterium avium } \\
\text { intracellulare }\end{array}$ & $\begin{array}{l}\text { Sarcoidosis } \\
\text { Low CD4 count } \\
\text { HIV-negative }\end{array}$ & $\begin{array}{l}\text { Resection } \\
\text { ATT } \\
\text { FU: } 1 \text { year and doing well }\end{array}$ \\
\hline Present case & $53 \mathrm{y} / \mathrm{M}$ & $\begin{array}{l}\text { Constitutional symptoms, slurring } \\
\text { of speech, upper limb weakness } \\
\text { for } 2 \text { months }\end{array}$ & $\begin{array}{l}\text { Multiple supratentorial and } \\
\text { infratentorial lesions }\end{array}$ & Mycobacterial culture negative & $\begin{array}{l}\text { HIV-negative } \\
\text { No evidence of } \\
\text { immunocompromised state }\end{array}$ & $\begin{array}{l}\text { ATT } \\
\text { Resection of right occipital lesion } \\
\text { FU: } 5 \text { months post-operative and } \\
\text { doing well }\end{array}$ \\
\hline
\end{tabular}

ART, anti-retroviral therapy; ATT, anti-tubercular treatment; FU, follow-up; M, male. 
He was a diabetic and hypertensive, on medications for the past 1 and 4 years, respectively, and HbA1c level in September 2019 was $9.0 \%$. Complete haemogram showed a total leukocyte count of 8200 cells $/ \mathrm{mm}^{3}$ (normal range 4000-11000 cells $/ \mathrm{mm}^{3}$ ) with $39 \%$ lymphocytes (normal range 20-40\%) and enzyme-linked fluorescent assay for HIV was negative. Surgery was planned to confirm tubercular pathology and to rule out any other possibilities like metastasis. Right occipital craniotomy and excision of the right occipital lesion was performed 6 months after the onset of symptoms. Intraoperatively, the lesion was seen surfacing in the right occipital lobe near the junction of torcula and transverse sinus. It was hard in consistency, grey-white, lobulated and mildly vascular with good planes with the arachnoid membrane and brain parenchyma. On sectioning, a small cystic cavity with whitish content was found within the lesion. The cyst content did not yield any growth on mycobacterial culture even after 8 weeks of incubation.

Microscopic examination of the lesion showed a wellcircumscribed lesion composed of compact fascicles of spindle cells admixed with lymphocytes and plasma cells. The spindle cells were CD68-positive and GFAP-negative. Occasional ill-formed granulomas and small cysts bordered by foamy macrophages and foci of necrosis were also present. Acid-fast bacilli were detected in both the spindled histiocytes and in the foamy macrophages in Ziehl-Neelsen stain (Fig. 1E-H). Based on these features, the lesion was diagnosed as mycobacterial spindle cell pseudotumour.

Mycobacterial spindle cell pseudotumour is characterised by a tumour-like proliferation of spindle shaped histiocytes containing acid-fast bacilli. It is generally associated with an immunocompromised state and can be caused by both tuberculous and non-tuberculous mycobacteria. In a study by Sfeir et al., ${ }^{6}$ out of the 51 cases of mycobacterial spindle cell pseudotumour, $51 \%$ were associated with HIV infection and $45.1 \%$ of cases involved the lymph nodes. Most commonly, Mycobacterium avium complex was isolated (47.1\%) followed by Mycobacterium tuberculosis complex $(16 \%)$.

The five documented cases of mycobacterial spindle cell pseudotumour affecting the brain are described in Table $1 .{ }^{1-5}$ All of them occurred in adult males (age range 38-66 years, mean 49.6 years). Of these, two cases were associated with HIV infection and presented as multiple intracerebral lesions. $^{2,4}$ The rest of the three cases ${ }^{1,3,5}$ had underlying sarcoidosis and two among them were treated with corticosteroids and had low CD4 count. ${ }^{1,5}$ Only a single case of mycobacterial spindle cell pseudotumour has been described in an apparently immunocompetent 63 -year-old male. ${ }^{3}$ In addition, dural based mycobacterial spindle cell pseudotumour in the right temporal region has also been described in association with sarcoidosis and pulmonary Mycobacterium avium complex infection.

The present case is the second case of intracerebral mycobacterial spindle cell pseudotumour to occur in an individual without any evidence of immunosuppression.
Due to its rarity and uncommon histomorphological pattern, it is important not to mistake mycobacterial pseudotumour for a spindle cell neoplasm. The presence of inflammatory infiltrate of small lymphocytes and plasma cells and presence of ill-formed granuloma indicate an infective process. Immunohistochemical markers like CD163 and CD68 will establish the histiocytic nature of the spindle cells, with CD163 being a more specific marker than CD68. Presence of acid-fast bacilli on Ziehl-Neelsen stain will confirm the tubercular aetiology. Antitubercular therapy is the mainstay of treatment with the majority of patients positively responding to the therapy. ${ }^{6}$

In conclusion, mycobacterial infections can present with the unusual morphology of a spindle cell pseudotumour even in immunocompetent individuals and should be included in the differential diagnosis of spindle cell lesions in the brain.

Conflicts of interest and sources of funding: The authors state that there are no conflicts of interest to disclose.

\section{Rajalakshmi Poyuran ${ }^{1}$, Dinoop K. Ponnambath ${ }^{2}$ George C. Vilanilam ${ }^{3}$, Kesavadas Chandrasekharan ${ }^{4}$, Deepti Narasimhaiah}

${ }^{1}$ Department of Pathology, Sree Chitra Tirunal Institute for Medical Sciences and Technology (SCTIMST), Trivandrum, India; ${ }^{2}$ Department of Microbiology, Sree Chitra Tirunal Institute for Medical Sciences and Technology (SCTIMST), Trivandrum, India; ${ }^{3}$ Department of Neurosurgery, Sree Chitra Tirunal Institute for Medical Sciences and Technology (SCTIMST), Trivandrum, India; ${ }^{4}$ Department of Imaging Sciences and Intervention Radiology, Sree Chitra Tirunal Institute for Medical Sciences and Technology (SCTIMST), Trivandrum, India

Contact A/Prof Deepti Narasimhaiah.

E-mail: kashyap_path10@yahoo.com

1. Morrison A, Gyure KA, Stone J, et al. Mycobacterial spindle cell pseudotumor of the brain: a case report and review of the literature. Am J Surg Pathol 1999; 23: 1294-9.

2. Phowthongkum P, Puengchitprapai A, Udomsantisook N, et al. Spindle cell pseudotumor of the brain associated with Mycobacterium haemophilum and Mycobacterium simiae mixed infection in a patient with AIDS: the first case report. Int J Infect Dis 2008; 12: 421-4.

3. Sadek M, Yue FY, Lee EY, et al. Clinical and immunologic features of an atypical intracranial mycobacterium avium complex (MAC) infection compared with those of pulmonary MAC infections. Clin Vaccine Immunol 2008; 15: 1580-9.

4. de Oliveira FH, Martins Antunes ÁC, Golbspan L, et al. Mycobacterium tuberculosis as cause of a cerebral spindle cell tumor in an HIV patient. Clin Neuropathol 2015; 34: 104-7.

5. Lim MS, Bermingham N, O'Broin C, et al. Isolated cerebellar spindle cell pseudotumor caused by mycobacterium avium-intracellulare complex in a patient without AIDS. World Neurosurg 2016; 90: 703.

6. Sfeir MM, Schuetz A, Van Besien K, et al. Mycobacterial spindle cell pseudotumour: epidemiology and clinical outcomes. J Clin Pathol 2018; 71: $626-30$.

7. Ismail I, Carey M, Trotter S, Kunst H. Mycobacterial spindle cell pseudotumour of the brain in a patient with sarcoidosis. BMJ Case Rep 2015; 2015: bcr2014206171. 
8. Lau SK, Chu PG, Weiss LM. CD163: a specific marker of macrophages in paraffin-embedded tissue samples. Am J Clin Pathol 2004; 122: 794801.

DOI: https://doi.org/10.1016/j.pathol.2020.11.013

\section{FNBP1-BRAF fusion in a primary melanoma of the lung}

\section{Sir,}

Primary melanomas of the lung (PML) are extremely rare lung cancers with less than 80 cases published in the English literature. $^{1-3}$ Indeed, metastases of cutaneous primary tumours account for most melanomas diagnosed in the lung, while few pulmonary primary cases are expected to derive from the melanocytes of the tracheo-bronchial apparatus. ${ }^{4}$ Limited genetic studies have been performed in this setting. We report a case of PML with a previously undescribed FNBP1-BRAF fusion.

The study was conducted according to the Declaration of Helsinki and was approved by the research ethics committee of the Center Leon Berard, Lyon, France (Ref: L20-72).

A 55-year-old woman, actively smoking (15 pack year) with a previous medical history of multiple sclerosis and arterial hypertension was referred to the pneumology department for the investigation of a para-mediastinal mass of the left lung. This $7 \mathrm{~cm}$ diameter tumour was discovered during medical investigation for recurrent bronchitis (Fig. 1A). A drill biopsy of the pulmonary mass was performed.

Microscopic examination revealed infiltration of the bronchial mucosa by an undifferentiated tumoural proliferation made of small to medium sized cells harbouring high nucleocytoplasmic ratio and numerous mitotic figures frequently associated with necrosis. No infiltration of the surrounding epithelium was evidenced (Fig. 1B,C).

Immunohistochemistry demonstrated focal expression of the S100 protein and SOX10. No expression of MelanA, HMB45, cytokeratins (AE1/AE3), EMA, chromogranin A, synaptophysin, CD45, CD34, CD99 or TTF1 was observed. Proliferation index (Ki-67) was estimated around $20 \%$. Extension work-up including a body scan positron emission tomography (PET) imaging and dermatological examination did not detect any other tumour location. The patient received chemotherapy (Holoxan and doxorubicine) before surgical resection.

Three years later, a superficial centimetric nodule arose on the right arm of the patient. Microscopic examination revealed dermal infiltration by tumour cells with medium size, amphophilic cytoplasm and large nucleus. No junctional component was detected. Immunohistochemistry confirmed expression of S100 (Fig. 1D) and SOX10, while no positivity was observed with the melanocytic markers HMB45, antiMelanA and anti-MITF. Whole exome RNA-sequencing performed in the skin tumour identified a FNBPI ENST00000446176 (e13)-BRAF ENST00000288602 (e9) fusion. Mutations in BRAF, NRAS, C-KIT, TP53 genes or $C R T C$-TRIM11 fusion were not evidenced. Furthermore, the $B R A F$ rearrangement was confirmed using a $B R A F$ fluorescence in situ hybridisation (FISH) break-apart probe in both the lung primary tumour and the skin metastasis that showed an identical unbalanced pattern with gain of the $3^{\prime}$ BRAF red signal in both samples (Fig. 1E).

Additional pulmonary and skin recurrences were detected with the PET scanner 6 years after the initial diagnosis. Biopsy of the skin tumour revealed a similar morphology to that previously described (Fig. 2A,B). Immunohistochemistry revealed expression of PS100, SOX10, MelanA and HMB45 in tumour cells (Fig. 2C-F). Presence of a BRAF fusion in the skin tumour was further confirmed by FISH again with a similar pattern.

The patient was treated with immune checkpoint inhibitors; however, bone and mediastinal lymph node metastases were detected 5 months after the final diagnosis.

Herein, we report a case of PML with a FNBP1-BRAF fusion. PML is an extremely rare tumour which accounts for $0.01 \%$ of primary lung cancers ${ }^{4}$ and metastatic melanoma appears as the main differential diagnosis in this setting. ${ }^{1,2}$ In 1968 Allen and Drash and in 1969 Jensen and Egedorf proposed that recognition of an intraepidermal component within the lung tumour might allow the distinction between primary tumours and metastasis. ${ }^{1,2}$ However, such findings were counteracted by the identification of intraepidermal involvement in pulmonary metastasis of cutaneous melanoma. Therefore, Wilson and Moran later defined PML as: (1) a solitary tumour, (2) malignant melanoma confirmed by immunohistochemistry, (3) no past history of excision for cutaneous, mucosal or ocular melanoma, (4) central pulmonary lesion, and (5) no demonstrable tumour elsewhere at the time of diagnosis. ${ }^{4}$ Accordingly, our case met these criteria at the time of diagnosis and, although a skin tumour was detected 3 years after the identification of the lung tumour, such large delay suggests it is unlikely that this cutaneous tumour was in fact a primary that had given rise to the lung location.

Although PML might initially arise from the bronchial apparatus, it could alternatively be regarded as a metastatic location of a so called malignant melanoma of unknown primary (MUP). ${ }^{6}$ While the origin of MUP is matter of debate, frequent detections of $B R A F, N R A S$ and $N F 1$ mutations, high mutation burden and prominent UV signature $(\mathrm{C}>\mathrm{T}$ transition) strongly argue in favour of a cutaneous origin for most of the MUP cases. ${ }^{7}$ In the PML setting, although no evaluation of the tumour burden and no research for mutational signatures have been conducted, the initial investigations in 10 PML cases (mainly isolated case reports) have not identified mutations in BRAF, C-KIT and NF1 genes. ${ }^{3}$ Therefore, the absence of common oncogenic drivers of cutaneous melanoma in PML suggests an extracutaneous origin for these cases, as similarly observed for mucosal melanomas. ${ }^{8,9}$ By contrast, recent investigations by Yang et al. of 10 additional PML cases revealed high tumour mutation burden, frequent $R A F, N R A S$, $N F 1, K I T$, or $K R A S$ mutations, and dominant UV-signature mutation profile, strongly arguing for a cutaneous primary origin in these 'PML' cases. ${ }^{10}$

In this context, we detected a previously unreported fusion of the $B R A F$ gene in a PML case. Indeed, although much less frequent than $B R A F$ and NRAS mutations, BRAF fusions, with a conserved functional serine-threonin kinase domain, are an alternative mechanism leading to the activation of the MAP kinases pathway. BRAF fusions have been detected in about $0.3 \%$ of solid cancers including pancreatic, lung, thyroid, colorectal, carcinomas and pilocytic glioma. In 